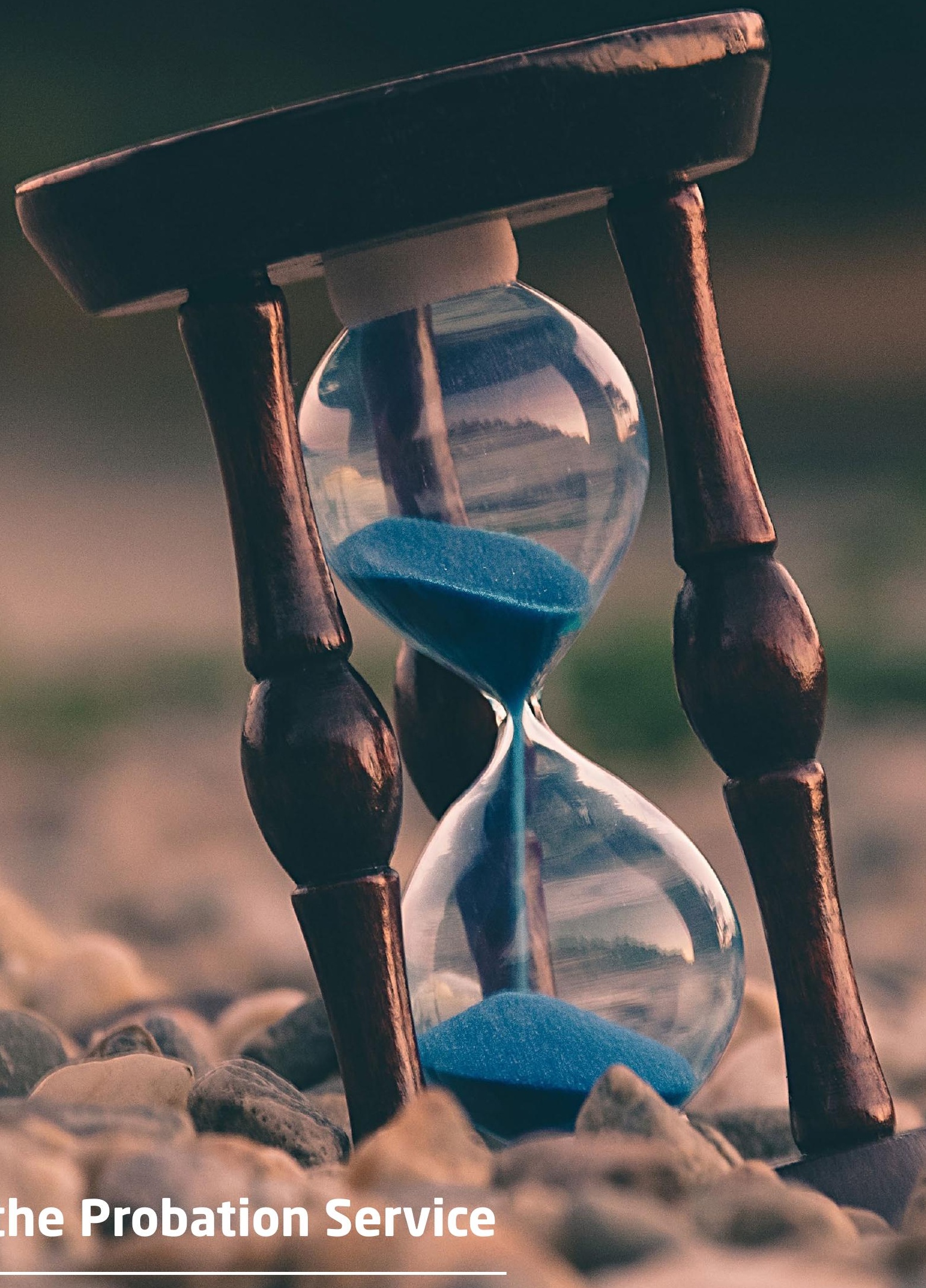

Jim Barton provides a personal reflection on the process of unification and offers some thoughts on what's next.

\title{
Unifying the Probation Service
}




\section{Countdown to unification}

Early on in my role as SRO for Probation Reform, I bought a digital timer to count down the months, days, hours and minutes until midnight on 25 June 2021 - The day we would become one unified probation system. The not-so-subtle reminder that we had a huge task ahead of us before it displayed a row of zeros became somewhat of a conversation piece in those early virtual team meetings.

Fast forward a few months and our programme team was running at pace. We'd attracted skilled people across a range of disciplines, from within and outside of probation, and everyone now had an acute appreciation of the scale of the challenge and our delivery deadline. People who admitted struggling to recall their family members' birthdays had 25 June 2021 etched on the brain. The timer had become redundant and I was secretly pleased to confine it to my desk drawer when the batteries ran out long before Day 1 of our new Probation Service.

\section{Day 1 of the Probation Service}

Our team put heart and soul into bringing together the very best of the NPS (National Probation Service) and CRCs (Community Rehabilitation Companies) into our now newly named 'Probation Service' - a name we felt was not too far from our roots but responded to feedback from our people that a new name was a strong signal of us being a new organisation. We had prepared to welcome more than 7,000 probation professionals either directly into

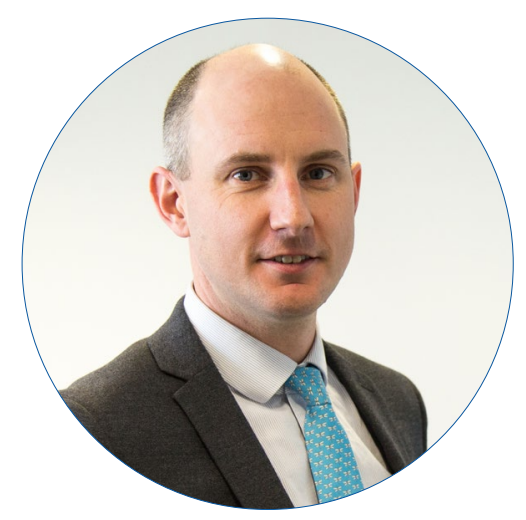

Jim Barton

Senior Responsible Owner - Probation Reform Programme and Electronic Monitoring Programme, Her Majesty's Prison and Probation Service, Ministry of Justice

our services or into our partner organisations appointed to deliver commissioned rehabilitative services. We had created an incredibly popular website specifically to be a one stop shop of information to support their transition. We had supplied new laptops and smartphones to home addresses, migrated terabytes of data and emails, connected 120 new offices and had a dedicated support structure in place, including a control room with 24-hour coverage, ready for the big day.

Everyone involved should feel incredibly proud of having pulled off the task of transitioning to our new structures on time and to plan. Inevitably there are challenges, and a huge amount of work still to be done, but we have achieved the first big step towards our future operating model. 


\section{Taking time to unify}

We're mindful that our transformation has put many of our people through a lot of change in a relatively short time period. We all adapt to change in different ways and at varied pace, so our focus now is to ensure that everyone completes a smooth transition and is content in their new work environment.

To support this, we are making minimal changes to our operational processes during this early post-unification period. Instead, we are focussed on ensuring the changes we designed to bring stability to the organisation are effectively embedded.

\section{Reforms built on solid foundations}

Our next step is to begin implementing the reforms set out in our Target Operating Model, published in February, that will improve how we protect the public and positively change lives.

Regional delivery is core to our plans for truly transforming our Probation Service. Drawing on our people's extensive local knowledge and empowering them to take accountability for partnership working and delivery of services will enable us to more closely meet the diverse needs of communities and people on probation.

In sentence management we are focusing on more consistent management and delivery of sentence plans, better assessment and management of risk and more balanced caseloads with an improved case allocation process to support this.

For Unpaid Work, Accredited Programmes and Structured Interventions we will be driving up completion rates and delivering better outcomes. We'll do this by making programmes available locally, making improvements to the assessment and induction process and more regular reviews of active cases.

We also have ambitions to put Unpaid Work hours to even better use, establishing more partnerships with national organisations to help improve the visibility of the punishment in local communities.

Our commissioned rehabilitative service providers are crucial in delivering services in Employment, Training \& Education, Accommodation and Personal Wellbeing and Women's Services. Backed by an initial government investment of $€ 195$ million, 26 organisations across England and Wales are now working closely with us to provide vital support in these interventions.

\section{Investing in our people}

Our staff are critical to the delivery of the new model and we have a comprehensive plan in place to support them to succeed in the new service. Our Probation Workforce Strategy, published last year, includes a professional register, underpinned by ethical and training standards, to ensure probation practitioners receive the training, qualifications and recognition they need and rightly deserve.

Of course, those joining our team can also expect this same high level of support. This applies to more than 1,000 probation officers we recently announced had been recruited and to an intake of a further 1500 planned for the year ahead.

\section{Find out more}

There has never been a more unique and exciting time for the Probation Service. If you are interested in finding out more about our reforms, do sign up to our Probation Changes Bulletin. 